\title{
ANTROPOLOGIA \& IMAGENS: O QUE HÁ DE PARTICULAR NA ANTROPOLOGIA VISUAL BRASILEIRA?
}

Clarice E. Peixoto ${ }^{1}$

UERJ, Rio de Janeiro, Brasil

\begin{abstract}
Este artigo apresenta os resultados de uma pesquisa sobre a antropologia visual brasileira (2013-2017), e analisou cinco centros de antropologia visual de universidades do Sul, Sudeste, Nordeste e Centro-Oeste. Três deles são coordenados por antropólogas visuais que compóem a primeira geração a obter essa formação, $e$ dois da segunda geração. O objetivo é conhecer o que há de especifico na antropologia visual brasileira: ela ainda permanece vinculada às escolas europeias el ou americanas ou já produz narrativas imagéticas próprias? Para isso, analisei a formação acadêmica dos professores-coordenadores, suas orientações teóricas, e as condições estruturais para a formação de novos pesquisadores nesse campo.

Palavras-chave: antropologia visual brasileira, qualificação em antropologia visual, gerações audiovisuais
\end{abstract}

\section{QUE ANTROPOLOGIA VISUAL FAZEMOS NO BRASIL?}

Essa indagação me intrigou durante muitos anos. Nos inspiramos nas escolas europeias como a de Jean Rouch e sua antropologia compartilhada, e/ou a de Paul Henley com o Granada Center? No cinema de observação americano, tendo David MacDougall como interlocutor mais frequente? Ou no cinema de Trinh Minh-ha? Talvez um pouco de cada, agregando outras referências do nosso campo? Será que produzimos narrativas imagéticas próprias?

A rápida ascensão da antropologia visual brasileira, e sua aquiescência nas instituições públicas de ensino superior e nas principais associações de representação das ciências sociais, ${ }^{2}$ se

1 Agradeço ao CNPq, Prociência/UERJ e aos bolsistas PIBIC desta pesquisa: D. Nigri, F. Boechat, N. Martins, V. Costa. Contato da autora: peixotoclarice@gmail.com.

2 Associação Brasileira de Antropologia/ABA e Associação Nacional de Pós-Graduação em Ciências Sociais/ ANPOCS. 
comparada às da Argentina, Colômbia, México e Chile, estimula a questionar e refletir sobre as bases de reprodução desse conhecimento no ensino e na pesquisa.

O crescimento dos grupos de antropologia visual, ${ }^{3}$ e o volume de trabalhos de conclusão dos cursos de graduação e pós-graduação ${ }^{4}$ suscitou uma questão de base: a da formação. Quem forma quem e como são qualificados os(as) antropólogos(as) visuais brasileiros(as)? Este foi o mote que me instigou a analisar os textos visuais (filmes etnográficos e ensaios fotográficos) e textos escritos (teses de doutorado e dissertações), e as condições estruturais oferecidas em alguns dos principais centros brasileiros de pesquisa em antropologia visual.

Tarefa árdua uma vez que a produção escrita \& audiovisual brasileira nesse campo é extensa! Impossível analisar a de todos os centros, pois hoje vinte e oito estão inscritos no site do Comitê de Antropologia Visual/CAV-ABA. ${ }^{5} \mathrm{Na}$ tentativa de construir um breve panorama da nossa antropologia visual selecionei dois grupos coordenados pela que considero a primeira geração de antropólogas(os) visuais e dois pela segunda geração, buscando não concentrar em uma só região do país. ${ }^{6}$ Outro ponto importante que direcionou esta seleção foi o de que estes centros deveriam apresentar certa continuidade na produção audiovisual, assim como na de teses e dissertações.

Voltando um pouco no tempo lembro que ao publicar um artigo, em 1992, sobre a antropologia visual no Brasil já apontava para a necessidade de "uma reflexão teórica sobre a utilização da linguagem cinematográfica na análise das questões sociais" (Peixoto 1992:56). O campo da antropologia visual desabrochava, incentivado pelos primeiros fóruns de divulgação e debate da produção nascente, principalmente, os Grupos de Trabalho da ANPOCS e da Reunião Brasileira de Antropologia/RBA. Esses fóruns eram (ainda são) enriquecidos com as sessões de apresentação dos filmes etnográficos e exposições fotográficas, e com os debates que provocavam. Importante assinalar o papel da Jornada de Antropologia Visual (1992-1994), organizada pelo NAVISUAL/UFRGS em Porto Alegre, e da Mostra Internacional do Filme Etnográfico (1993-2013), no Rio de Janeiro.

Nesse primeiro momento, a dificuldade enfrentada pelos(as) pesquisadores(as) era a de convencer seus colegas e universidades de que a aquisição de equipamentos audiovisuais e fotográficos era fundamental para o desenvolvimento de suas pesquisas com imagens. Ana Maria Galano já apontava para esse desafio:

Devido a inexistência de práticas de ensino com imagens em cursos de graduação em ciências sociais no Brasil, a invenção pedagógica no $\mathrm{NAVEDOC}^{7}$ talvez tenha sido ainda mais acentuada. (...). Começamos a trabalhar sem equipamento, sem financiamento para a compra de material sensível e sem profissionais da imagem e do som. (Galano 1998:175).

\footnotetext{
3 Noção de Antropologia Visual inspirada nas escolas europeia e americana dos anos 1960/1970, e que estimulavam a produção de filmes etnográficos e fotografias no fazer antropológico.

4 Difícil quantificar essa produção. Desde os anos 1980 acompanho a apresentação de papers nos congressos brasileiros e latino-americanos e a publicação de artigos e livros.

5 Site do Comitê de Antropologia Visual/CAV-ABA https://cavantropologiavis.wixsite.com/cavaba

6 Nota metodológica no final.

7 Núcleo Audiovisual de Documentação/NAVEDOC-IFCS/UFRJ, primeiro grupo brasileiro de pesquisas com imagens (1987).
} 
No final da década de oitenta, quando a construção do campo da antropologia visual buscava se afirmar nas universidades europeias, os centros de formação que lá surgiam também não tinham infraestrutura adequada para o ensino da antropologia visual, exceto a Universidade de Manchester que, em 1987, criou o Granada Centre voltado e equipado para o mestrado em antropologia visual, ${ }^{8}$ posteriormente também doutorado. Nesta década, algumas universidades francesas criaram cursos de antropologia visual como a École des Hautes Etudes en Sciences Sociales/EHESS (1989) com o seminário dirigido por M-H. Piault, E. Latour e J-P. Colleyn. Depois dos anos 1990 surgiram outros como o Laboratoire d'Anthropologie Visuelle et Sonore du Monde Contemporain/Universidade Paris VII (1992), de Jean Arlaud. A maioria desses cursos franceses não dispunha de equipamentos (câmeras, ilha de edição, etc.) para essa formação, delegando essa responsabilidade aos estudantes.

Interessante assinalar a ausência de diálogo e de intercâmbio entre eles, ainda que promovessem "cursos, projeções, festivais e manifestações. Nos cruzávamos um com outro e isso revelava bem as clivagens existentes nesta disciplina que começava a se definir. Havia Jussieu, Nanterre, Museu do Homem, EHESS, EPHE e, se os estudantes podiam circular entre uma ou várias escolas, o seu pertencimento era exclusivo". ${ }^{9}$ (Wanono Gauthier 2014:430).

Desde o início, MacDougall afirmava que uma cultura cinematográfica empobrecida produziria filmes moldados na linguagem televisiva, o que não era apropriado para o cinema documentário. Assim, "é essencial que as escolas disponibilizem para os seus estudantes uma diversidade ampla de filmes documentários" (1998:226). Rouch, nas aulas da Cinemateca Francesa e da Universidade Paris X-Nanterre, sempre dizia que "é vendo filmes que aprendemos a fazer filmes".

Sabemos que o uso social da imagem, consumida e mesmo produzida desde a infância, leva a crer que o seu aprendizado é inútil já que essa socialização é internalizada como um saber ao longo dos anos. Podemos, muito rápido e sem dificuldade, produzir fotografias e filmes de família ou de viagens com câmeras digitais simples e, cada vez mais, com suportes como celular e tablet. Contudo, essa facilidade aparente é uma enorme limitação quando se produz imagens etnográficas.

Por isso, tanto MacDougall quanto Rouch insistiam na formação de uma cultura visual e no aprendizado de técnicas de filmagem, conhecimentos que eles transmitiam aos seus alunos. ${ }^{10}$

E no Brasil? Ensinamos teorias, linguagens \& técnicas? Os centros de antropologia visual dispõem de acervo de imagens (filmes e fotografias) para consulta, estimulando seus estudantes

8 Segundo Paul Henley, o Granada Centre foi criado no departamento de antropologia da Universidade de Manchester por David Turton, Leslie Woodhead e Marilyn Strathern, à época diretora deste. (Peixoto e Caiuby Novaes 2008).

9 Traduções de inglês e francês são de minha autoria.

10 Em 1952, Rouch criou o Comitê do Filme Etnográfico no Museu do Homem, onde muitos antropólogos se formaram, inclusive Galano em 1967. Em 1977 ele inaugurou o primeiro curso de pós-graduação de antropologia visual: Cinéma, Télévision et Audiovisuel/Cinéma Anthropologique, Universidade de ParisX-Nanterre, também sem equipamentos. Em 1950, a Universidade de Göttingen/Alemanha criou o Institut for Scientific Film, cujo objetivo era produzir filmes científicos com rígidos critérios acadêmicos baseados em uma compreensão positivista da cultura. Posteriormente, Peter Fuchs redirecionou a antropologia visual alemã e seu modo de conceber o filme etnográfico e a antropologia visual. 
à aquisição de cultura audiovisual? Afinal, o que ensinamos e como o fazemos? Quais são as nossas referências teóricas e audiovisuais?

\section{ANTROPOLOGIA VISUAL BRASILEIRA}

Já há algumas décadas, a antropologia visual vem refletindo sobre que tipo de conhecimento as imagens propõem à análise das práticas e representações, e que relações elas podem estabelecer com a realidade social. Sabemos que a linguagem imagética tem mais expressividade e força metafórica, condensa e torna a percepção dos fenômenos sociais mais sensível, já que é mais alusiva e simbólica ainda que nem sempre mostre exaustivamente a riqueza dos dados etnográficos (Peixoto 1998). Sem dúvida, as imagens contêm informações importantes que "expressam a história social e política, os modos de vida, as práticas, o cotidiano, bem como as manifestações dos sistemas simbólicos, do imaginário social com seus códigos e representações" (Mignot-Lefebvre 1987:227). Pois,

Por meio de imagens uma sociedade constrói, sobre si, um discurso visual. Esta construção deve ser entendida num sentido amplo. Se, por um lado, ela é obra daquele que capta as imagens ou do diretor do filme, por outro lado, no caso de filmes em que não há atores profissionais, como aqueles feitos por antropólogos - os chamados filmes etnográficos -, esse discurso visual é também obra dos próprios 'informantes'. (Caiuby Novaes 2004:12).

A análise dessas imagens não é imediata e a formação para sua leitura, e para a desconstrução dos seus códigos, é parte inerente a esta abordagem. Ela é, na verdade, uma condição.

Considerando que o trabalho antropológico é uma experiência no campo das percepções, dos sons, odores, gostos, sensações táteis e tantas outras, na qual mobilizamos todos os sentidos, e que na fabricação das imagens a escuta e o olhar são mais aguçados, a pesquisa antropológica com imagens nos faz mergulhar mais profundamente no campo do compreensível. Entretanto, o trabalho na pesquisa de campo não significa apenas 'sentir' as sensações do Outro, e sim conhecer as categorias que designam essas sensações e, principalmente, perceber as diferenças entre aquelas do sujeito filmado-fotografado e as do fabricante das imagens. Nessa abordagem, frequentemente designada como antropologia participante, o antropólogo se deixa levar pelas ações dos sujeitos observados, preservando, no entanto, sua intenção primeira: a compreensão das representações e práticas sociais do grupo estudado. (Peixoto 2000).

Os debates sobre a crise da writing culture e as questões da subjetividade e da reflexividade abriram mais espaço à narrativa audiovisual (e às outras narrativas antropológicas), bem como para as novas tecnologias que deram à antropologia visual um lugar de destaque na pesquisa antropológica (Pink 2006). Se no passado, esse campo enfrentou dificuldades para ser aceito pela antropologia clássica, hoje, ele exerce um papel crítico importante na formação teórica e prática da antropologia contemporânea. Isto porque "as imagens dão sentido à nossa compreensão do que é a realidade social, do que foi ou do que poderá vir a ser” (Nichols 2001:2).

Outra prerrogativa da antropologia visual é a possibilidade de transpor as fronteiras acadêmicas via cinema e exposições fotográficas, revelando para um público mais amplo a dinâmica social retratada. É fundamental assinalar que o filme e a fotografia ultrapassam as possibilidades de registro do tradicional caderno de campo permitindo acompanhar, sobretudo no filme, o 
visível (práticas, gestos e movimentos) e o invisível (falas, risos, choros e silêncio) de uma relação face a face; não somente aquela que se estabelece entre o observador e o sujeito observado (e vice-versa), mas sobretudo, as relações tecidas entre os membros dos grupos estudados. Esta é uma das características do trabalho audiovisual: a relação entre aquele que filma/fotografa e aquele que é filmado/fotografado é refletida na imagem, pois a câmera é o pivô relacional na elaboração dessas imagens (Peixoto 1998, 2000). Nesse sentido, a própria relação que eles mantêm com o instrumento (e com a sua imagem e a dos outros refletida no visor da câmera) é um elemento imprescindível para a interpretação das interações sociais e a construção das representações individuais e coletivas.

Foi a partir desses parâmetros que a antropologia visual brasileira deu seus primeiros passos no final dos anos 1980. Surgiram os primeiros núcleos/grupos de antropologia visual nos departamentos de antropologia e ciências sociais. ${ }^{11}$ Outros foram criados nas décadas seguintes e, hoje, na maioria das universidades públicas brasileiras existe um centro de antropologia visual.

\section{Da formação}

A análise do currículo Lattes/CNPq dos vinte e oito coordenadores dos centros inscritos no site do Comitê de Antropologia Visual/CAV-ABA revela que alguns deles não têm nenhuma formação no campo da imagem (fotográfica, cinematográfica, artes em geral), em nenhum nível (incluindo especialização e curso técnico). São autodidatas.

Talvez permaneça a ideia de que a única dificuldade para produzir imagens é de ordem técnica e, assim, basta saber manipular o instrumento e sair por aí com 'uma câmera na mão e uma ideia na cabeça'12 (Glauber Rocha, anos 1960). Contudo, Glauber trabalhava cuidadosamente os seus roteiros "preocupado com a criação de uma estética cinematográfica e uma mensagem política que fossem verdadeiramente revolucionárias. (...) um processo minucioso de planejamento do filme pelo cineasta, que realizou várias viagens pelo sertão nordestino e fez pesquisas rigorosas sobre o cangaço" (Monzani 2006:251), antes de filmar Deus e o Diabo na Terra do Sol (1964). No prefácio deste livro, Xavier escreve:

Muita confusão se criou em torno da máxima glauberiana - 'uma câmera na mão e uma ideia na cabeça' como se houvesse aí implicada a ideia de elementar improviso, pouca atenção ao trabalho de preparação dos filmes. Toma-la à letra, de forma redutora, é esquecer a enorme auto-exigência e o angustiado trabalho de criação de um cineasta realizador de obra complexa, onde 'ideia' envolve um rico processo de reflexão e de ensaio nos caminhos de expressão, e 'câmera na mão' significa abraçar uma nova estética de construção do olhar e da mise-en-scène que se ajusta à escassez de recursos e faz, de um problema, um motivo de criação. (2006:15)

Glauber Rocha rompeu fronteiras e paradigmas ao refutar o cinema dominante, construindo uma narrativa com o efeito estético do documentário e uma câmera ágil que se aproximava e distanciava-se das pessoas e das coisas, lembrando Jean Rouch.

11 Dentre os ativos, os primeiros foram o NAVISUAL/UFRGS (1990), o LISA/USP (1991) e o INARRA/ UERJ (1994). Dois outros se destacam: NAVI/UFSC e LAV/UFPE.

12 Frase que foi um dos pilares do cinema novo brasileiro inspirado na nouvelle vague francesa e no neorrealismo italiano, contestadores da estética e da narrativa dos filmes comerciais da época. 
Hoje, com as novas tecnologias digitais que permitem maior autonomia de gravação - sem a interrupção frequente para a troca de bobinas -, e que incitam ao registro sem limites, este mito do total improviso não se adequa mais ao cinema documentário, e tampouco à antropologia visual dado que, em geral, esse procedimento produz imagens que não dizem nada etnograficamente. Assim, "a antropologia visual não é sobre o visual per se, mas sobre uma gama de relações culturalmente influenciadas, enredadas e codificadas no visual” (MacDougall 1997:288). Desse modo, ela deve considerar "a contribuição que o filme [e a fotografia] pode dar para a antropologia como uma disciplina teórica" (Murphy e Banks 1997:5). Assim, "o desafio mais substancial do pensamento antropológico não vem simplesmente da ampliação de sua esfera de ação, mas a partir de sua entrada em sistemas de comunicação diferentes da 'antropologia das palavras"' (MacDougall 1997:285).

Nesse sentido, entendo que a antropologia visual não é uma subdisciplina da antropologia, mas um domínio especializado e profundamente vinculado às questões e problemas próprios da antropologia. Pois, se considerada como subdisciplina, a integração/incorporação das imagens na antropologia tenderá à mera ilustração, criando uma dicotomia maior entre imagem e escrita.

Sabemos que imagens e palavras constituem elementos dos processos de representação e que nessa relação existem práticas discursivas específicas para melhor expressar culturas e dinâmicas sociais. No discurso imagético, a produção de imagens etnográficas exige do pesquisador o conhecimento dessa linguagem (cinematográfica, fotográfica, iconográfica, web) para que ele possa considerar os elementos de composição do enquadramento (construção e edição de planos e ângulos de um filme/fotografia), e melhor explorar o registro e a compreensão dos processos sociais e culturais. Tri Minh-ha, apesar de conhecer essas regras, decidiu rompe-las ao realizar seu primeiro filme Reassemblage (1982): usou lente grande angular e evitou closes, desconstruindo as convenções ocidentais de representação sobre outras culturas (Crawford 1992).

Como, então, ensinar antropologia visual sem evocar essas questões? Para entender como esse conhecimento é transmitido analisei a formação dos professores-coordenadores dos centros aqui estudados, os programas dos cursos de pós-graduação e bibliografias, as oficinas práticas e demais atividades. Por fim, os trabalhos de conclusão do doutorado de seus orientandos/ as e aqueles dirigidos por essa segunda geração. ${ }^{13}$

Os três grupos coordenados pela primeira geração de antropólogas visuais são: GRAVI/ Grupo de Antropologia Visual e LISA/Laboratório da Imagem e Som em Antropologia (USP); Núcleo de Antropologia Visual/NAVISUAL e BIEV/Banco de Imagens e Efeitos Visuais (UFRGS); Imagens e Narrativas/INARRA (UERJ). Os dois da segunda geração: Núcleo de Antropologia Visual/NAVIS (UFRN); Laboratório de Imagem e Registro de Interações Sociais/IRIS (UNB). ${ }^{14}$ A diferenciação é importante porque mostra a sedimentação de uns e o desenvolvimento de outros, revelados pelas condições estruturais (salas, equipamentos, equipe, acervos), mas principalmente, pela produção audiovisual incorporada aos trabalhos de conclusão de curso. Ou seja, a formação sistemática de novos pesquisadores neste campo. A partir das

13 Nas teses de doutorado/dissertações busquei nos títulos, resumos e palavras-chave indicadores de que as imagens integravam a pesquisa (produção ou análise). Aquelas sem nenhuma referência nestes itens foram desconsideradas. Analisei suas bibliografias acessíveis nos websites das pós-graduações ou universidades com o objetivo de descobrir, por meio dos autores de referência, certa influência de uma ou outra escola.

14 NAVIS/UFRN criado em 2001 e IRIS/UNB em 2011. 
teses de doutorado e da inserção institucional destes pesquisadores é possível construir genealogias da antropologia visual brasileira, tendo esses grupos como referência.

Vejamos as condições estruturais: os grupos de antropologia visual possuem equipamentos para produção/edição de imagens? Eles têm acervo de filmes para consulta e análise com vistas à formação de uma cultura visual e de conhecimento de técnicas de produção de imagens, tal como indicado por MacDougall e Rouch?

Dos grupos aqui analisados todos têm um espaço próprio e equipamentos de filmagem, fotografia e edição. Alguns têm câmeras semiprofissionais, outros handycams mais simples. Há que destacar o LISA/USP que dispõe de uma estrutura invejável: auditório de 40 lugares, salas para secretaria, reuniões, visionamento e acervos (fílmico e fotográfico); laboratório fotográfico; estúdios de edição e de som; câmeras semiprofissionais e handycams, microfones e gravadores diversos, etc.

Os demais grupos têm instalações menores, uma ou duas salas onde tudo acontece: reuniões, visionamento, edições. E tudo se guarda: acervos de filmes, fotografias, livros, equipamentos, etc. Ver apresentação completa da produção de cada um nos respectivos sites e blogs sinalizados na nota metodológica.

Se todos os centros produzem filmes, nem todos dispõem de acervo fílmico. Eis aqui uma questão de geração: os três mais antigos possuem uma ampla videoteca com filmes em suporte DVD. O LISA\&GRAVI tem o maior acervo: cerca 1.800 filmes e 15.000 imagens (fotos, cromos e chapas de vidro), além de livros, teses e catálogos. O NAVISUAL tem um acervo de mais de 600 títulos (filmes, entrevistas filmadas, registros sonoros) e biblioteca (livros, trabalhos conclusão, etc.). O INARRA cerca de 800 títulos e biblioteca (livros, catálogos de festivais, revistas etc) acessíveis aos professores e estudantes ${ }^{15}$. Dos dois núcleos da segunda geração, o IRIS tem cerca de 450 títulos e o NAVIS redireciona seus estudantes para filmes disponíveis na internet ou arquivados em HD externo, o que dificulta a circulação e o visionamento/empréstimo do acervo.

Há alguns anos indaguei "sobre que tipo de imagens, qual a duração, quais os tipos de planos, quais os ângulos e os enquadramentos devemos filmar aquilo que consideramos pertinente para o tratamento do objeto?”. Alertava que o ensino paralelo das linguagens e técnicas audiovisuais e da web era fundamental para essa formação (Peixoto 1998:219). Pois, não se trata simplesmente de transferir questões e problemáticas sócio-antropológicas para a tela, é preciso conhece-las para melhor explorar a produção e a leitura do seu conteúdo etnográfico.

Nesse sentido, diria que o LISA\&GRAVI e o INARRA são os centros que mais sistematicamente promovem oficinas de fotografia, filmagem \& som, muitas delas dirigidas por especialistas especialmente contratados. São também os que mais organizam colóquios a nível nacional e internacional, criando maior interlocução entre brasileiros e estrangeiros. Já o NAVISUAL consolidou suas parcerias latino-americanas em intercâmbios com universidades chilenas e argentinas.

15 O INARRA sugere filmes aos professores para seus cursos, estimulando formação de cultura visual. Possui duas salas (multimídia e edição) e equipamentos para filmagem e fotografia. 
A dinâmica de reuniões internas parece ser constante em todos.

\section{SOBRE GERAÇÕES DE ANTROPÓLOGOS/AS VISUAIS}

Geração é um termo polissêmico de uso universal, construído como categoria sociológica no século passado. Não tenho a intenção de aprofundar a teoria das gerações, distinguindo os fenômenos de geração daqueles de idade e cujas questões as ciências sociais se debruçaram desde então. Apenas me inspirei para diferenciar os grupos e antropólogos(as) audiovisuais aqui referidos(as), dado que se trata de refletir sobre a construção desse campo no Brasil e seus desdobramentos ao longo dos tempos. Porém, entendo que geração designa uma relação de contemporaneidade entre os indivíduos ligados por princípios de socialização e que "formam um tipo de comunidade espiritual, mesmo dispersos no espaço, e que têm afinidades devido ao modo como são formados por experiências comuns" (Attias-Donfut 1991:27).

O interesse pela produção e análise de imagens reuniu, no final dos anos 1980, um grupo de pesquisadores(as) para discutir pesquisa \& imagens. Considero que esta foi a primeira geração de antropólogos(as) visuais brasileiros(as), a mesma que criou os primeiros centros universitários de pesquisa nesse campo. Se nem todos(as) tiveram uma formação doutoral, alguns(as) realizaram pós-doutoramento em antropologia visual fora do país, pois acreditam que para fazer pesquisa com imagens é fundamental saber como uma imagem produz etnografia. Para esta geração, e nela me incluo, a formação teórica e prática é fundamental, pois produzir imagens é uma outra forma de fazer teoria.

É bem verdade que poucas pessoas dessa primeira geração tinham familiaridade com a realização de filmes (seja filme de família ou de viagem), sendo mais afeitas à produção de fotografias amadoras. Caiuby Novaes (LISA\&GRAVI) foi uma exceção. Fotografou desde a infância, o que para as novas gerações é uma prática corrente que permite uma progressiva familiaridade com as técnicas: ${ }^{16}$

Ganhei uma máquina fotográfica quando tinha cinco, seis anos. A vida inteira eu fotografei, e sempre gostei de cinema. Sempre gostei mais de fotografia. [...]. Fiz o mestrado em 1980 e o doutorado em 1990. Tanto meu mestrado como meu doutorado já têm muitas fotografias. E desde que comecei a pesquisar os Bororo, em 1970, sempre fotografei em pesquisa. E muito!

Rapidamente descobri que a fotografia era um elemento fundamental para estabelecer contato e para discutir com os Bororo os temas que não estavam em pauta. Ou seja, eu levava a foto que continha de algum modo o que eu queria discutir, e ela colocava o tema em pauta. Em pesquisa de campo você não consegue discutir no abstrato uma coisa que não esteja acontecendo. Mas a partir da fotografia, ela cria o contexto do tema que você quer discutir. [...]. Em setembro 1993 fui fazer o pós-doutorado em Manchester. Fiz esse mestrado em antropologia visual no Granada Center, mesmo tendo doutorado, porque nessa época lá não tinha doutorado.

Eckert e Rocha, coordenadoras do NAVISUAL e BIEV (UFRGS) fizeram pós-doutorado (2001) na Universidade Paris VII com Jean Arlaud. Rocha pertence a uma família ligada 
às artes e ela mesma fez teatro, performance e artes visuais antes de mergulhar na antropologia visual. ${ }^{17}$

A formação nesse campo pressupõe, para nós, a necessidade de conhecer a história do cinema, seus narradores e fabricantes de imagens - das cronofotografias aos primeiros filmes. Sem este conhecimento e sólida formação teórica pensamos ser impossível refletir sobre o que produzimos. Assim, ao lançar mão de meios audiovisuais para entender os sujeitos, construir e divulgar o saber antropológico é importante conhecer as narrativas imagéticas e suas formas de produção.

A análise do currículo Lattes/CNPq da segunda geração de coordenadores dos centros estudados revela que nem todos buscaram formação em antropologia visual como, por exemplo, os do IRIS/UNB. Os currículos de Sautchuk e Simião informam que ambos fizeram doutorado na UNB onde hoje trabalham, seus orientadores não são antropólogos(as) visuais e não há referência de que tenham realizado cursos nesse campo ou áreas afins. Contudo, a leitura dos programas das disciplinas que eles ministram revela que elas discutem noções de produção cinematográfica, linguagens e aspectos técnicos. No item áreas de atuação do Lattes/CNPq também não consta antropologia visual nos seus currículos. Interessante que na avaliação do primeiro Roteiro de Classificação de Produção Audiovisual (Capes, triênio 2010-2013), ${ }^{18}$ o IRIS apresentou uma alta produção audiovisual.

Coradini, coordenadora do NAVIS/UFRN, doutorou-se em antropologia visual na Universidade Autônoma do México. Mas, seu interesse por filme documentário era anterior: ${ }^{19}$

Em 1995 assisti um programa de televisão onde a cangaceira Cila falava sobre sua vida e experiência no cangaço. Achei maravilhoso e que daria um documentário fantástico! Entrei em contato e disse que queria fazer um filme sobre a vida dela. Ela topou!

Por coincidência participei de um concurso de roteiros e fiquei entre os cinco selecionados do Brasil. Recebi uma verba, telefonei pra Cila, disse que tinha o recurso e queria fazer sua trajetória pelos caminhos do cangaço. A partir daí tudo começou.

Tanto ela quanto o seu núcleo apresentam uma consistente e permanente produção de textos, filmes etnográficos \& ensaios fotográficos. Não é à toa que foi o grupo de pesquisa mais produtivo do Nordeste nessa primeira avaliação da Capes.

No INARRA, seus membros pertencem à primeira e segunda geração. Como disse, minha formação doutoral foi em antropologia social e visual e realizada em duas etapas: Diplôme d'Etudes Approfondies/DEA na 'escola de Rouch' (Paris X-Nanterre, 1988-1989), um curso de formação mais técnica e voltado para linguagem cinematográfica; e doutorado na EHESS (1990-1993). ${ }^{20}$ Compõem a segunda geração do INARRA pesquisadores com doutoramento

17 Entrevista realizada 03/2012.

18 Consultar Capes em https://docs.google.com/viewer?a=v\&pid=sites\&srcid=Y2FwZXMuZ292LmJyfHRyaWVuYWwtMjAxM3xneDo0MGY3ZTczMTQzZTJhOGM2 p.21. O INARRA não participa desta avaliação porque é da área de Sociologia/Capes, que ainda não aprovou o Roteiro de Produção Audiovisual.

19 Entrevista realizada 12/2014.

20 Em 1989, E. Latour, J-P. Colleyn e M-H. Piault, ex-alunos de Rouch no Comité du Film Ethnographique, coordenaram o primeiro curso de antropologia visual da EHESS e criaram o Atelier d'Anthropologie Visuelle. Finalizado o DEA/Nanterre me inscrevi nesse doutorado da École onde aprendi a fazer antropologia com imagens, sendo a primeira a defender tese de doutorado nesse campo, sob a direção de Piault. 
sob minha orientação e aqueles que aderiram à antropologia visual $\&$ artes, mesmo sem ter formação específica anterior.

Passemos às gerações de antropólogos(as) visuais. Analisei as teses de doutorado concluídas até outubro de 2018 e construí a trajetória dos pesquisadores formados pela primeira geração, curiosa em descobrir se já estão inseridos institucionalmente e transmitindo o conhecimento recebido nesse campo. ${ }^{21}$ Vejamos, a primeira geração do LISA\&GRAVI qualificou doze doutores em antropologia visual, dos quais sete estão inseridos em universidades públicas. Esta segunda geração já formou três doutores e vinte e três mestres, que constituem a terceira geração de antropólogos(as) visuais. $\mathrm{Na}$ análise das teses de doutorado do NAVISUAL\&BIEV só encontrei quatro delas em antropologia visual ${ }^{22}$, seus autores são professores de universidades públicas e já formaram dois mestres da terceira geração. O NAVIS formou seis pesquisadores, dos quais quatro estão em instituições públicas e já qualificaram sete mestres. O IRIS não tem nenhuma tese em antropologia visual. O INARRA qualificou nove pesquisadores em antropologia visual, e essa segunda geração já formou três doutores e oito mestres. Quanto à inserção profissional três estão em universidades públicas, três em universidades privadas e dois em outras instituições públicas.

Esta análise permite perceber que a maioria das teses de doutorado/dissertações divulgadas como realizadas no campo da antropologia visual não contém palavras indicativas nas 'ferramentas de busca' (título, resumo, palavras-chave). Ou seja, elas não fazem nenhuma referência à imagem, filme, fotografia, desenho, iconografia, televisão, web, internet, multimídia, etc. Exemplo disso são o IRIS e o NAVISUAL, cuja leitura das teses revela que muitas produzem/analisam imagens, mas infelizmente não indicam nestas ferramentas que elas pertencem a este campo.

Uma lacuna lastimável porque a ausência dessas referências impede revelar a especificidade metodológica - etnografia audiovisual - de construção do conhecimento, reforçando a ideia de que prevalece apenas a produção imagética, desvalorizando a produção teórica em antropologia visual.

Os trabalhos em antropologia visual, orientados pela segunda geração, sugerem uma ruptura na transmissão desse conhecimento uma vez que também não apresentam estas ferramentas de busca.

\section{Sobre a inspiração}

Diria que a maioria dos pesquisadores acima tem como principal referência fílmica a obra de Rouch, sendo os filmes mais citados Les Maîtres Fous e Moi, un Noir, ainda que outros sejam mencionados para aludir o ciné-transe. ${ }^{23}$ Os textos de MacDougall constam da maioria das

21 Data de defesa da tese para conhecer o tempo de inserção institucional e análise dos seus currículos para identificar a orientação de teses e dissertações no campo. Fonte: Plataforma Lattes/CNPq 26/10/2018.

22 Só foram consideradas as teses/dissertações que apresentaram ferramentas de busca (imagem, fotografia, filmes, etc.) no título ou resumo ou palavras-chave. Ver nota 13.

23 Diz Rouch: "Para mim, a única maneira de filmar é andar com a câmera, conduzi-la lá onde ela é mais eficaz, e improvisar um outro tipo de balé no qual a câmera se torne tão vivaz quanto os homens que ela filma (...). Assim, no lugar de usar o zoom, o diretor-cameraman penetra realmente no seu objeto, antecede ou segue o dançarino, o 
bibliografias da antropologia visual brasileira, enquanto seus filmes são menos referidos. Talvez porque eles estejam mais próximos ao estilo cinema de observação, ${ }^{24}$ ainda que sua atual démarche seja mais interativa do que observadora, como revelam os seus cinco filmes sobre a Doon School, ${ }^{25}$ na Índia. Este cinema interativo proposto por MacDougall não é similar ao cinema compartilhado $^{26}$ e ao ciné-transe de Rouch porque o filme interativo se expressa "na escolha das pessoas a serem filmadas, na posição da câmera, na distância entre o cineasta e as pessoas filmadas" (MacDougall 2006). Sobretudo, na troca de olhares e na relação que o cineasta cria com seus sujeitos, e não necessariamente no diálogo revelado nos campos sonoro e visual.

Entendo por filmes de inspiração aqueles que sugerem ideias de narrativas, de maneiras de ver e conhecer os sujeitos, e indicam elementos técnicos mais específicos para a construção das imagens \& sons. ${ }^{27}$ É possível perceber perspectivas distintas nas produções literárias e audiovisuais dos centros da USP e UFRGS. A antropologia visual paulista mantém relações estreitas com arte e performance, daí talvez a maior inspiração em Rouch e recentemente em T. Minh-ha para pensar a narrativa fílmica. Sem dúvida MacDougall é referência constante nos textos sobre filme etnográfico. Diria que a literatura mais consultada sobre imagem fotográfica é bastante focada na semiótica (C. Pierce, R. Barthes, P. Dubois entre outros) e na antropologia visual anglo-saxônica (E. Edwards, J. Collier, Mead/Bateson, S. Sontag, e outros). O LISA\&GRAVI se destacam dos demais por essa proximidade com arte e performance e com trabalhos realizados em parceria com o grupo NaPedra ${ }^{28} / \mathrm{USP}$, coordenado John Dawsey.

Já os projetos realizados no centro gaúcho propõem estudar as memórias coletivas inspiradas na etnografia da duração, optando "pelo desenvolvimento do estudo das imagens, com as imagens, pelas imagens seguindo a obra de Bachelard" (Eckert e Rocha 2012). Os trabalhos ali desenvolvidos propõem descrever e interpretar a fenomenologia dos conteúdos da imaginação na perspectiva proposta por G. Durand, para tratar da universalidade dos arquétipos. Os estudos com etnografia da duração do NAVISUAL\&BIEV analisam narrativas biográficas e formas de sociabilidade no mundo urbano porto-alegrense, e "refletem sobre o estatuto que a representação etnográfica desempenha no contexto da cultura visual do mundo contemporâneo local" (idem).

padre, o artesão, ele não é mais ele mesmo, mas um 'olho mecânico' acompanhado de uma 'orelha eletrônica'. É esta transformação bizarra da pessoa que chamo, em analogia aos fenômenos de possessão, de ciné-transe” (1979:63).

24 Criado nos anos 1960 por Colin Young, Universidade da Califórnia, o ‘observational cinema’ propõe filmar a realidade social sem a intervenção do cineasta para que as cenas revelem as dinâmicas sociais e as expressões culturais tal como se desenrolam, sem interagir e solicitar às pessoas filmadas que refaçam a cena.

25 Doon School Chronicles (2000), With Morning Hearts (2001), Karam in Jaipur (2001), The Nerw Boys (2003), The Age of Reason (2004).

26 Há várias leituras sobre o cinema compartilhado de Rouch. Entendo que 'câmera participante' é a comunicação direta com as pessoas filmadas, estar com elas para "se adaptar à ação em função do espaço, e penetrar na realidade em vez de a deixar se desenrolar diante do observador” (Rouch 1979:63). Não só, o feedback das imagens às pessoas filmadas e suas reações - o contra dom audiovisual - complementa a ideia de antropologia compartilhada; "um estímulo ao conhecimento mútuo e à dignidade dos sujeitos filmados". Nessa linha de interpretação considero que 'troca antropológica' é um termo mais adequado para designar essa dinâmica da produção de imagens etnográficas. (Peixoto 1995:93).

27 Na elaboração da minha tese e do filme que a acompanha assisti documentários que foram fundamentais para a criação de uma narrativa fílmica que melhor revelasse as relações de sociabilidade na velhice em Paris e Rio de Janeiro.

28 Núcleo de Antropologia, Performance e Drama. 
Os trabalhos do NAVIS/UFRN também estão mais dirigidos para as temáticas urbanas, tendo como foco a cidade de Natal, incluindo questões que envolvem meio ambiente e populações tradicionais, mas igualmente as temáticas relativas à imagem. Nos últimos anos, o NAVIS criou uma interlocução com o cinema africano; ${ }^{29}$ Rouch e seu colega angolano Duarte Carvalho são, sem dúvida, as principais inspirações cinematográficas, assessoradas pelas teorias pós colonialistas de E. Said e A. Appadurai.

O IRIS/UNB tem característica diferente: uma das áreas de interesse é a antropologia da técnica e do corpo revelada tanto na bibliografia dos cursos de antropologia visual quanto nos ensaios fotográficos produzidos. Nesses campos, a principal inspiração é Marcel Mauss e os trabalhos produzidos na escola de Paris-X-Nanterre baseados nas técnicas corporais. As metodologias de pesquisa com imagens fotográficas propostas por Mead / Bateson e E. Samain fazem parte, igualmente, do corpus de inspiração visual desse grupo.

Até recentemente o INARRA/UERJ estava focado apenas nas narrativas fílmicas e fotográficas dado meu interesse por essas linguagens. Como participei dos tempos de grande efervescência da antropologia visual francesa com profusão de ateliês, festivais e exposições, minha inspiração maior é sem dúvida a escola francesa. Nesses espaços de exibição e debate conheci antropólogos-cineastas anglo-saxões cujos filmes e textos também influenciam minhas pesquisas. Sem dúvida, D. MacDougall, P. Henley, J. Marshall e P. Crawford estão entre os meus outros respiros. A segunda geração de pesquisadores do INARRA incorporou novos campos - Arte, Performance e Cinema - e novas inspirações: Z. Bauman, A. Gell, J. Clifford, A. Rosenthal, R. Stam, entre outras.

Há autores que estão presentes na maioria das referências da antropologia visual brasileira como R. Barthes, W. Benjamin, G. Deleuze e F. Guattari, M. Mead e G. Bateson, G. Marcus, P. Hockings, B. Nichols e, principalmente, D. MacDougall.

Uma triste constatação. Pouco nos referimos à literatura brasileira de antropologia visual. E. Samain e M. Moreira Leite são os mais frequentes na fotografia. Mas, em filme etnográfico somos muito autocentrados. Se a inspiração é internacional, a expiração é endogâmica posto que referida, principalmente, aos trabalhos produzidos no interior do próprio grupo de pesquisa.

\section{FINALIZANDO}

Em 1992, o Journal des Anthropologues publicou seu primeiro dossiê dedicado à antropologia visual. Sarah Pink, recém-formada no mestrado de antropologia visual de Manchester, ainda estudante de doutorado, finalizou seu artigo dizendo que o estatuto da antropologia visual ainda era bastante ambíguo:

Podemos considera-la como um domínio especializado e, nesse caso, ela está diretamente ligada a todos os problemas próprios a esta disciplina. Se se mantem a ideia de que a antropologia visual é uma subdisciplina da antropologia, isso pode depreciar a integração das imagens na antropologia social. Como, então, a antro- 
pologia visual deveria se integrar no trabalho dos antropólogos?

Nesta situação, para os que são formados em antropologia visual existe a oportunidade de serem, ao mesmo tempo, especialistas junto àqueles que desejam sua assessoria e de serem antropólogos que usam a dimensão visual nas suas pesquisas e na apresentação de seus trabalhos. (Pink 1992:129-130).

Ao longo dos anos, Pink desenvolveu pesquisas e reflexões que permitiram explorar a relação entre novos meios digitais, teoria antropológica e antropologia visual aplicada. ${ }^{30}$ Para ela, o futuro da antropologia visual do século XXI implica na interdisciplinaridade, "em novas formas de prática visual, novos modos de produção visual, de conteúdo, disseminação e interpretação, talvez combinados em novas inter-relações com outros elementos da experiência sensorial" (2006:141). Para entender a eficácia dessa proposta é importante pensar como as categorias, as práticas e a agência são construídas e constituídas nos diferentes contextos culturais, pois, "uma nova antropologia visual que combine imagem e palavra pode oferecer uma contribuição rica para as ciências sociais" (idem p.140).

Chegamos ao século XXI com todos esses questionamentos e múltiplas experiências. Desde seu surgimento a antropologia visual brasileira ampliou a sua perspectiva, revelando a riqueza da interdisciplinaridade e de como as novas tecnologias audiovisuais estão inseridas na produção de cultura, nas práticas e comportamentos, na construção de sentidos e identidades. Uma disciplina dinâmica posto que incorpora, incessantemente, as inovações tecnológicas ao seu ofício, promovendo uma releitura de temas clássicos antropológicos. As novas gerações de antropólogos(as) visuais estão mais conectadas com as tecnologias de imagem e som, focalizando seus interesses nestes antigos temas, agora revisitados, e integrando novas temáticas, novas linguagens e narrativas e os inúmeros meios visuais para comunicar o saber antropológico. Mas, para dar maior e melhor visibilidade à nossa antropologia visual ela tem que ser anunciada nos títulos, palavras-chave e resumos dos nossos textos escritos, para que não constem apenas nos créditos dos textos audiovisuais. Mais ainda, temos que voltar nosso olhar para o quê e como estamos produzindo nesse campo, assim como buscar inspiração em nossos pares, respirar nossos ares.

À indagação inicial - Será que produzimos narrativas metodológicas próprias? - diria que temos uma antropologia visual híbrida que ainda muito se inspira dos ares europeus e americanos na tentativa de construir uma escola própria. Essa conjunção de centros e seus modos de pensar e produzir revela a nossa particularidade e dinâmica. Essa diversidade de escolhas parece destacar a antropologia visual brasileira uma vez que ela incorpora outros suportes como desenho, performance, mídias impressa e televisiva, internet, celular, entre outros, no seu campo de produção e análise de imagens, criando uma antropologia visual distinta e diversificada.

\section{NOTA METODOLÓGICA}

À impossibilidade de analisar todos os grupos de antropologia visual defini como critérios de seleção: 1. Universo de pesquisa composto por dois dos primeiros núcleos/laboratórios/ grupos (1980/1990) e dois mais recentes (anos 2000); 2. Centros inscritos em Universidades de quatro regiões do Brasil; 3. Baseada na primeira avaliação do Roteiro de Avaliação dos Produtos

30 Argumentação que resultou em The Future of Visual Anthropology. Engaging Senses, 2006. 
Audiovisuais/Capes/Antropologia (2010-2013) selecionei os que apresentaram a maior produção de filmes e ensaios fotográficos nesse triênio: LISA\&GRAVI-USP e NAVISUAL\&BIEVUFRGS, mais antigos e alta produção de teses de doutorado e produtos audiovisuais; NAVISUFRN e IRIS-UNB centros mais novos e alta produção de filmes/ensaios fotográficos. Agreguei os grupos da USP e os da UFRGS já que seus membros pertencem a ambos. O GRAVI é um grupo de pesquisa do Diretório de Grupos de Pesquisa/CNPq, enquanto o LISA é um laboratório com estrutura e equipamentos (http://www.lisa.fflch.usp.br). NAVISUAL "é um espaço para a divulgação do material etnográfico produzido por pesquisadores e para a discussão do uso de técnicas audiovisuais na pesquisa antropológica' (http://www.ufrgs.br/ppgas/nucleos/ navisual/); o BIEV 'integra as novas tecnologias digitais e eletrônicas no tratamento multimídia e hipermídia de coleções etnográficas' (http://www.ufrgs.br/biev/). Ambos pertencem ao Diretório CNPq assim como o NAVIS (https://navisufrn.wordpress.com/), mas não o IRIS (https:/www.facebook.com/iris.dan.35) apesar de seus coordenadores liderarem/pertencerem a outros grupos de pesquisa do Diretório CNPq. O INARRA (http://www.inarra.com.br), inscrito no Diretório CNPq desde 1994, é o quinto elemento deste universo para forçar um olhar para dentro e comparar com o olhar para fora.

As informações foram adquiridas em entrevistas, observação de cursos e oficinas de antropologia visual e reuniões; em levantamento das pesquisas e projetos financiados pelas agências, equipamentos, etc. Analisei 85 teses DO e 89 de ME orientadas por pesquisadores destes centros e disponíveis nos sites dos Programas. Os dados sobre pesquisas, financiamentos, programas de curso e oficinas, equipamentos e entrevistas do IRIS/UNB foram obtidos por e-mail.

Os nomes dos coordenadores foram mantidos porque são do conhecimento público, divulgados nos sites e blogs dos grupos de antropologia visual.

\section{REFERÊNCIAS BIBLIOGRÁFICAS}

Attias-Donfut, Claudine. 1991. Générations et âges de la vie. Paris: PUF.

Barthes, Roland. 1984. A câmara clara: notas sobre a fotografia. Rio de Janeiro: Nova Fronteira.

Bateson, Gregory, Margaret Mead. 1942. Balinese character: a photografic analysis. New York:

New York Academy of Sciences.

Benjamin, Walter. 1987. Magia e técnica, arte e politica. São Paulo: Brasiliense.

Caiuby Novaes, Sylvia. 2004. "Imagem em foco nas Ciências Sociais". Pp.11-18, em Escrituras da imagem, editado por S. Caiuby Novaes et al. São Paulo: Edusp.

Collier, John. 1973. Antropologia Visual: a fotografia como método de pesquisa. São Paulo: Editora Pedagógica Universitária/EDUSP.

Crawford, Peter. 1992. "Film as discourse: the invention of anthropological realities". Pp.66$82 \mathrm{em}$ Film as ethnography, editado por P. Crawford, D. Turton. New York: Manchester University Press.

Dubois, Philippe. 1994. O ato fotográfico. São Paulo: Papirus.

Eckert, Cornélia, Ana Luiza, Rocha. 2012. "Imagens do tempo e as ressonâncias das memórias coletivas: etnografias da duração nas cidades contemporâneas”. Em Imagens e Narrativas, editado por C. Peixoto et al. Rio Janeiro: INARRA, CDRom. ISBN 978-85-86065-10-1.

Edwards, Elizabeth. 1994. Anthropology and Photography 1860-1920. London: Yale University Press. 
Galano, Ana Maria. 1998. "Iniciação à pesquisa com imagens”. Pp.173-193 em Desafios da Imagem. Fotografia, iconografia e vídeo nas Ciências Sociais, editado por B. Feldman-Bianco, M. Moreira Leite. São Paulo: Papirus.

Koury, Mauro. 1999. "A Imagem nas Ciências Sociais do Brasil: um balanço crítico". BIBRevista Brasileira de Informação Bibliográfica em Ciências Sociais 47:49-63.

MacDougall, David. 1997. “The visual in anthropology”. Pp. 276-295 em Rethinking Visual Anthropology, editado por Banks, Marcus e Morphy, Howard. Yale University Press. 1998. Transcultural Cinema. Princeton: Princeton University Press. . 2006. “Conversas com MacDougall”. Lisa/USP. http://www.lisa.fflch.usp.br/node/68

Mignot-Lefebvre, Yvonne. 1989. "Le saltimbanque et le sociologue. Espace et reconstruction de la mémoire, à propos du film Fil de vies". Pp.55-68 em La caméra sur le terrain. Vaucresson: Centre de Recherche Interdisciplinaire/CNRS.

Monzani, Josette. 2006. Gênese de Deus e o Diabo na Terra do Sol. São Paulo: Annablume.

Nichols, Bill. 2001. Introduction to Documentary. Indiana University Press.

Peixoto, Clarice e Caiuby Novaes, Sylvia. 2008. "Paul Henley: o antropólogo-cineasta que faz cineastas". Revista de Antropologia 51(2):765-785.

Peixoto, Clarice. 1992. "Anthropologie visuelle au Brésil”. Journal des Anthropologues 47/48:4758. Trad. Cadernos de Antropologia e Imagem 1:75-80, 1995.

1995. "O jogo dos espelhos e das identidades: as observações comparada e compartilhada”. Horizontes Antropológicos 2:87-106.

1998. "Caleidoscópio de imagens: o uso do vídeo e a sua contribuição à análise das relações sociais”. Pp.213-224 em Desafios da Imagem. Fotografia, iconografia e vídeo nas ciências sociais, editado por B. Feldman-Bianco, M. Moreira Leite. São Paulo: Papirus.

. 2000. Envelhecimento e Imagem: as fronteiras entre Paris e Rio de Janeiro. São Paulo: Annablume/FAPERJ. Filme: Em busca do pequeno paraíso. Paris, 1993.

Pierce, Charles. 1999. Semiótica. São Paulo: Perspectiva.

Pink, Sara. 1992. "Nouvelles perspectives après une formation à l'anthropologie visuelle". Journal des Anthropologues 47/48:123-130.

. 2006. The future of Visual Anthropology. Engaging the Senses. London \& New York: Routledge.

Rosenthal, Alan. 1988. New challenges for documentary. Berkeley: University of California Press.

Rouch, Jean. 1979. "La Caméra et les Hommes". Pp.53-71 em Pour une anthropologie visuelle, editado por C. De France. Paris: Mouton.

Sontag, Susan. 1981. Ensaios sobre fotografia. Rio de Janeiro: Arbor.

Stam, Robert. 2003. Introdução à teoria do cinema. Campinas: Papirus.

Wanono Gauthier, Nadine. 2014. "Hommage à Jean Arlaud (1938-2013)". Journal des Anthropologues 136/137:429-434.

\section{ANTHROPOLOGY \& IMAGE: WHAT IS PARTICULAR IN BRAZILIAN VISUAL ANTHROPOLOGY?}

This article presents the results of a research on Brazilian visual anthropology (2013-2017), which
studied five centres for visual anthropology of universities in the South, Southeast, Northeast and
Midwest. Three of them are coordinated by visual anthropologists - the first generation with this
training -, and two are of the second generation. The article's purpose is to inquire what is particular
to Brazilian visual anthropology. Does it remain strongly based on the European and/or American 
schools, or does it already produce its own methodological narratives? To answer this question, I analyze the academic qualification of the coordinators-professors, their theoretical orientations, and the structural conditions for the formation of new researchers in this field.

Keywords: Brazilian visual anthropology, visual anthropology training, audiovisual generations

Recebido em: 2018-06-17

Aceitado em: 2018-11-20 